\title{
Videolaryngoscopes in Paediatric Anaesthesia
}

\section{Claire Wallace, $M B C h B, F R C A^{*}$ Thomas Engelhardt, MD, PhD, FRCA}

\author{
Address \\ *Department of Anaesthesia, Royal Aberdeen Children's Hospital, Westburn Road, \\ Aberdeen, AB25 2ZG, Scotland, UK \\ Email: clairewallace3@nhs.net
}

Published online: 27 January 2015

(C) Springer International Publishing AG 2015

This article is part of the Topical Collection on Pediatric Critical Care Medicine

Keywords Paediatric · Videolaryngoscope - Intubation - Airway - Difficult - Infant - Neonate

\section{Opinion statement}

The use of videolaryngoscopy is an ever expanding and developing branch of both routine and advanced airway management. An array of 'tried and tested' videolaryngoscopes is increasingly being used routinely in adults. However, due to the anatomical differences between adults and children, the proposed benefits are not readily transferrable without supporting evidence. With an increase in paediatric-sized equipment, the last 10 years has seen a rise in the number of relevant clinical investigations in the use of videolaryngoscopes for paediatric airway management. This narrative review focuses on videolaryngoscopes currently available for paediatric patients. The supporting literature is analyzed for their clinical use and effectiveness.

\section{Introduction}

A range of videolaryngoscopes (VL) for routine and advanced airway management has been introduced into adult and paediatric anaesthetic practice and they are here to stay. Each current paediatric VL has been introduced as a 'down-size' of the primary adult version. VL are frequently classified in adult practice according to their shape, angulation and presence of guidance channel [1]. However, comprehensive clinical studies about the effectiveness for routine daily practice or difficult airways in children are sparse and only poorly documented. Currently, the following VL are commercially available with paediatric sizes: GlideScope ${ }^{\circledR}$ (Verathon Medical Devices), DCI Video Intubation Systems (Karl-Storz Endoscope), TruView PCD (Truphatek), Airtraq (Prodol) and McGrath Series 5 (Aircraft Medical Ltd.) (Table 1).

The following sections describe each VL in turn and assess its use and potential applications for clinical practice. 


\begin{tabular}{|c|c|c|}
\hline Laryngoscope & Advantages & Disadvantages \\
\hline \multirow[t]{3}{*}{ GlideScope ${ }^{\circledR}$} & High-quality images & Fogging of image \\
\hline & Ability to exact length of $T$ beyond vocal cords & Difficulty advancing TT \\
\hline & Teaching aid & Reports of intra-oral injury in adults \\
\hline \multirow{2}{*}{ Storz DCI } & High-quality images & Cost \\
\hline & Part of all in one system & Maintenance \\
\hline \multirow[t]{3}{*}{ Bonfils } & Improved laryngeal view & Cost \\
\hline & $\begin{array}{l}\text { Narrow diameter for use in patients with limited } \\
\text { mouth opening }\end{array}$ & Secretions obscuring image \\
\hline & Steep, quick learning curve & \\
\hline \multirow[t]{2}{*}{ C-MAC } & High-quality images & Large handle \\
\hline & Portable & \\
\hline \multirow[t]{2}{*}{ TruView PCD pediatric } & Oxygen insufflation & Unfamiliar technique for use \\
\hline & Anti-fogging of camera & \\
\hline \multirow[t]{2}{*}{ Airtraq } & Portable & Posterior displacement of TT \\
\hline & Disposable & Good mouth opening required \\
\hline \multirow[t]{2}{*}{ McGrath series 5} & Portable & Size restrictions \\
\hline & Low maintenance & \\
\hline
\end{tabular}

\section{Paediatric videolaryngoscopes}

\section{GlideScope $^{\circledR}$}

\section{Description}

The Canadian-made GlideScope ${ }^{\circledR}$ VL have been available for clinical use in adults since 2001 with paediatric versions available since 2005. It has various models including the GlideScope ${ }^{\circledR}$ VL, the Titanium, the AVL (predecessor GVL Cobalt) and the Ranger, all with paediatric sizes. The blade is angled to $60^{\circ}$ with an inbuilt reusable video camera at the inflection point allowing a real-time, continuous, digital view of the airway on a separate colour monitor. The image is illuminated by a light-emitting diode near the end of the blade. The blade is inserted in the midline into the vallecula, and the tracheal tube (TT) is passed styletted to match the blade curvature, often referred to as a 'hockey stick' shape [2].

\section{Advantages}

Most case reports confirm the superior image of the larynx on the monitor with the ability to exact the length of TT beyond the vocal cords [3]. The GlideScope ${ }^{\circledR}$ is also perceived as a teaching aid for tracheal intubation in novice operators [3, 4].

The latest addition (GlideScope ${ }^{\circledR}$ Titanium) boasts lightweight strength and durability with a range of compatible blades including low-profile, angled 
GlideScope ${ }^{\circledR}$ blades and more familiar 'Mac-style' blades. They are also compatible with the GlideScope ${ }^{\circledR}$ blades already available for preterm and small children.

\section{Disadvantages}

The potential for intra-oral injury is described in several case reports in adults due to a potential 'blind spot' of the orophayrnx when the operator focuses solely on the video monitor [5-7]. This, however, is easily avoided by adopting a four-step technique as previously recommended: 1) look into the mouth and insert the blade, 2) look at the screen to see the larynx, 3) look into the mouth to insert TT and 4) look at the screen for intubation [8]. In addition to intra-oral injury, a case series including five neonates reported 'fogging' of the image and problems advancing the TT [4].

\section{Non-clinical evidence}

Recent comparative trials in simulator scenarios by non-anaesthetist candidates have largely favoured direct laryngoscopy over the GlideScope ${ }^{\circledR}$. Two SimBaby ${ }^{\circledR}$ investigations showed no significant difference in the time to successful intubation or the number of attempts required. In one trial, the GlideScope ${ }^{\circledR}$ gave a better view of the larynx and led to a less dental trauma in both normal and difficult simulated airways but did not improve the intubation time in simulated normal or difficult airways [9-11]. Indirect VL comparing the Cobalt GlideScope ${ }^{\circledR}$ has failed to show significant differences between its use and direct laryngoscopy or the Storz DCI VL in simulated normal and difficult airways $[12,13]$.

\section{Clinical evidence}

In 2012, Vlatten et al. published work which contradicted the majority of adult studies, concluding that when compared to direct laryngoscopy, GlideScope ${ }^{\circledR}$ VL significantly decrease percentage of glottis opening (POGO) scores and take a significantly longer time to gain the best view [14]. Subsequent studies have failed to confirm all aspects of this report. The majority of paediatric GlideScope ${ }^{\circledR}$ studies indicate a significantly better view of the larynx $[15 \bullet, 16,17]$ but at the expense of longer times to intubation [17-19]. Several studies reported no significant difference in the number of intubation attempts, view of the glottis, degree of difficulty and use of Magills forceps between the GlideScope ${ }^{\circledR}$ and direct laryngoscopy in normal airways [20-22]. In addition, a pilot study into difficult airways showed a significant improvement in the Cormack-Lehane view gained with the $\mathrm{VL}$, and no significant difference in time to generate best view when compared to direct laryngoscopy [16]. Although most studies showed a significantly longer time to intubate with the VL, these times were not clinically relevant.

A case series of three older children (ages 5, 6 and 15 years) with Goldenhar Syndrome and predicted difficult airways reported successful use of the GlideScope ${ }^{\circledR}$ Cobalt Infant VL [23]. In particular, the authors 
commented that the smaller and narrower infant GlideScope ${ }^{\circledR}$ may offer benefit in intubating older children with retro- and micrognathia.

\section{Verdict}

The current studies suggest that the GlideScope ${ }^{\circledR}$ is a suitable alternative to routine laryngoscopy in normal airways but would potentially be more advantageous in anticipated difficult airways or as a rescue device.

Storz videolaryngocopes

\section{Description}

Karl Storz endoscope has developed the DCI ${ }^{\circledR}$ Video Intubation System. It incorporates a single camera that can be easily connected to a variety of intubating devices such as the (BERCI-KAPLAN) DCI ${ }^{\circledR} \mathrm{VL}$, Bonfils intubation endoscope and flexible intubation fibrescopes. Continuous high-resolution video can then be simultaneously viewed on a separate monitor.

The DCI ${ }^{\circledR}$ VL integrates the endoscopic camera with an ergonomic handle which can be attached to a series of blades in both adult and paediatric sizes, namely the Miller 0 and 1 blades and the Macintosh 2 . Importantly, the blades are already familiar to practicing technicians, and the video lens is situated near the end of the blade by the light source giving an $80^{\circ}$ view angle.

The Bonfils is a rigid endoscope with its distal tip angulated $40^{\circ}$ which in turn gives a $110^{\circ}$ viewing angle. The camera is on the tip of the endoscope and allows simultaneously viewing of the TT as it passes through the vocal cords into the trachea.

Also available from Karl-Storz is the C-MAC VL, a more compact and portable version of the DCI ${ }^{\circledR} \mathrm{VL}$. It has a smaller, lightweight monitor that still produces high-resolution images, but it allows the kit to be easily moved.

\section{Advantages}

Overall, the Karl-Storz DCI ${ }^{\circledR}$ Video Intubation System gives an 'all in one' solution with the ability to choose the instrument that is best for your patient. In particular, the DCI ${ }^{\circledR} \mathrm{VL}$ offer a familiar design and approach to use with the benefit of high-quality images viewed separately by the operator, assistants and trainees. The Bonfils is marketed as the only instrument currently available which guarantees safe insertion of the TT because glottis and TT are in view simultaneously. Its narrow design is beneficial in patients with limited mouth opening. The C-MAC $\mathrm{VL}$ offers the same benefits as the DCI ${ }^{\circledR} \mathrm{VL}$ but with increased portability and has been used out of hospital.

\section{Disadvantages}

The $\mathrm{DCI}{ }^{\circledR}$ Video Intubation System is expensive and maintenance is potentially both specialized and costly. Specific drawbacks highlighted from the Bonfils 
endoscope is the lack of a port to allow suctioning of secretions and drug administration $[24,25]$.

\section{Non-clinical evidence}

In a manikin-based study simulating both normal and difficult airway scenarios, there was no difference in the time to intubate using the Karl-Storz DCI compared to the GlideScope ${ }^{\circledR}$ VL [12]. In addition, there were no differences in the secondary outcomes such as field of view and ease of use. In other infant and neonatal manikin studies, the Storz VL has shown better glottic views and POGO scores when compared to direct laryngoscopy, but not necessarily a reduction in intubation time $[26,27]$. A greater 1st attempt success rate and shorter intubation times with the videolaryngoscope compared to direct laryngoscopy in simulated intubations of neonatal and infant manikins were reported [28].

A SimBaby study by paediatric anaesthetists in 2010 concluded that the Bonfils intubating endoscope was easier to use and provided better views compared to direct laryngoscopy, but the success rates of intubation and times to achieve intubation were not improved [29].

\section{Clinical evidence}

The Karl-Storz video intubation systems are used for both the normal and the difficult paediatric airway. The DCI ${ }^{\circledR}$ VL provides better Cormack-Lehane views in children with anticipated normal airways. This was at the expense of statistically but not clinically increased time to intubate [30]. Similar outcomes were found in a study in children under 4 years old [31] and in young children during manual in-line stabilization [32] The $\mathrm{DCI}^{\circledR} \mathrm{VL}$ was reported to result in faster intubation and fewer numbers of failed intubations when compared with the GlideScope ${ }^{\circledR}[19]$ A limited comparison in children less than 2 years indicated no difference in success rate between the Storz and Airtraq VL with the latter providing faster intubation times [33]. The $\mathrm{DCI}^{\circledR} \mathrm{VL}$ is used increasingly in term as well as preterm neonates and is reported to improve the visibility for both the operator and assistant. Additional advantages include the teaching and supervision opportunities as well as the options to record and archive videos [34].

A steady stream of case reports continues to be published advocating the use of the Storz DCI Video laryngoscope in children with known difficult airways. Five such reports, totaling 11 children under 15 months, conclude that it improved the glottic view and allowed easy intubation where direct laryngoscopy had failed [35-39]. In addition, two of these cases were successfully intubated using the Storz DCI where the GlideScope ${ }^{\circledR}$ and Bonfils VL had previously failed [35, 38]. As well as the obvious improvement in view and intubation success, all reports stress the benefit of the Storz DCI as a teaching aid.

When compared to the GlideScope ${ }^{\circledR}$ VL, the Bonfils provided significantly better views and significantly faster times to intubation in children with normal airways [40]. This study also commented that the continuous view of the tracheal passage was a major advantage. In a small study of 50 children with normal airways, the Bonfils was found to significantly improve laryngeal views compared to direct laryngoscopy; however, intubation was not easier and there was a higher incidence of failure to intubate in the Bonfils group [41]. This potential for a higher rate of failure to intubate has been reported previously, 
and all failures were due to secretions obscuring the image and the failure to produce a pharyngeal space with an additional laryngoscope [42]. More recently, the Bonfils endoscope has been clinically compared to 'gold standard' fibreoptic intubation in children with difficult airways. This unique trial found that the Bonfils was easier to use than the fibreoptic intubation system and produced better quality images and faster times to intubate [43•].

The use of the Bonfils in children with difficult airways has been advocated in a sample of case reports where it has provided successful intubation where other instruments have failed [44-46]. One case commented specifically on the benefit of using the Bonfils over conventional direct laryngoscopy, LMA, GlideScope ${ }^{\circledR}$ VL and Airtraq in children with reduced intraoral space due to the narrow, rigid stylet [46].

The C-MAC VL has shown superiority to the TruView Infant EV02 in infants with normal airways in terms of ease of use and faster intubation times [47]. In the limited number of case reports available, it has proved advantageous over various intubation techniques including fibreoptic intubation in children with challenging airways [48]. However, mechanical problems in accessing the oral cavity may occasionally limit its use [49].

\section{Verdict}

The Karl-Storz DCI ${ }^{\circledR}$ Video Intubation System appears beneficial both in routine and difficult airway management as well as a potential rescue tool. A particular advantage is the use as a teaching aid for direct laryngoscopy. The evidence favours its use in all age groups and in children with both normal and difficult airways. In particular, the Bonfils should be considered in children with predicted difficult intubation where the mouth opening or intra-oral space is limited.

\section{TruView}

\section{Description}

The TruView PCD Pediatric is an optical laryngoscope with an eyepiece on the handle that can be connected to a video monitor. Its predecessor was the TruView Infant EV02. The design gives a wide and magnified view of the larynx for the operator. Its slogan is 'for even the toughest pediatric airway,' and it is advertised as 'superior access for difficult cases' including patients with restricted mouth opening and those immobilized. However, in line with other VL, only limited studies and case reports support this claim. There are four paediatric-sized blades available to facilitate intubation of newborns ( $\geq 800 \mathrm{~g}$ ) to obese teenagers.

\section{Advantages}

A unique feature of the TruView PCD laryngoscope is a port between the blade and handle for connecting an oxygen supply. The advantage is twofold: 1) oxygen insufflation to the airway and 2) anti-fogging of the camera.

\section{Disadvantages}

The design of the TruView is very unique and will be unfamiliar to new handlers, as will the technique required to use it successfully. In addition, 
although there is a port to supply oxygen during laryngoscopy, without external pressure, there is no guarantee of oxygen flow into the lungs which are static.

\section{Non-clinical evidence}

At the time of conducting this review, non-clinical evidence of the TruView VL was limited to adult simulators. In a study of novice operators with simulated normal and difficult airways, the TruView VL was found to provide better glottis views, but it did not always reduce the time needed to intubate or the difficulty of intubation. In difficult airway scenarios, the TruView took longer to intubate than standard Macintosh blade and was found to cause more dental clicks, an indication of dental trauma. Operators reported the manipulation of the TruView to be difficult [50].

\section{Clinical evidence}

The number of published trials of the TruView laryngoscope is low and focuses on children with normal airways. A recent comparative study of the TruView Infant EV02 PCD and the C-MAC VL in infants up to 22 months found both laryngoscopes produced excellent views of the vocal cords; however, the time to intubate was significantly longer in the TruView group [47]. The inbuilt safety feature did not prevent peripheral oxygen saturations to drop below $90 \%$ [47]. This is consistent with a previous study where, compared to conventional direct laryngoscopy, the use of the TruView EV02 resulted in longer times to intubate and lower $\mathrm{SpO}_{2}$ [51]. Two studies of neonates and infants with normal airways found the TruView laryngoscope to give superior glottic views but longer times to intubate compared to direct laryngoscopy $[52,53]$.

In terms of ease of use, the TruView has been scored as the least intuitive to use when compared to the C-MAC VL and Macintosh direct laryngoscope but is likely due to the differing clinical experience of the operators [47].

Two case reports have supported the use of the TruView PCD in children with difficult airways $[54,55]$. In both cases, one aged 7 months and the other an 8 day-old premature infant, tracheal intubation was achieved where conventional laryngoscopy with straight and curved blades had failed. The port for continuous oxygen insufflation was commended in the neonate with apneic spells [55].

\section{Verdict}

Studies into the use of the TruView laryngoscope are few but, so far, suggest that despite producing good views of the larynx, it takes significantly longer to achieve intubation. Currently, it does not appear to provide superiority in any aspect compared to other videolaryngoscopes.

\section{Airtraq}

\section{Description}

The Airtraq is a single-use, optical laryngoscope with an eyepiece on the handle which can be attached to a camera to allow video viewing on a wireless monitor. The array of available sizes accommodates neonate to adult patients 
with the smallest size 0 infant scope fitting size 4.0-5.5 tracheal tubes. It consists of two parallel channels, one with the optical and anti-fogging system and a guide channel for the TT. To use, the laryngoscope is inserted into the mouth in the midline and passed into the vallecula. To pass the TT successfully, the vocal cords need to be in the centre of the view field and the manufacturers describe a 'back-and-up' manoeuvre to achieve this.

As well as the disposable Airtraq SP model, there is now a reusable version with disposable blades, the Airtraq Avant, available in two adult sizes only.

\section{Advantages}

It is a very portable device and has been used in several hospital locations as well as in pre-hospital scenarios.

\section{Disadvantages}

Earlier case reports have highlighted a couple of potential problems that may be encountered when attempting intubation with the Airtraq. Firstly, despite obtaining good glottis views, passing the TT through the vocal cords is not always easy $[56,57]$. The shape of the laryngoscope tends to displace the tube posteriorly as it is advanced, and it is not always possible to overcome this with external manoeuvres or aids. Secondly, the laryngoscope is bulky compared to conventional blades making its use in patients with smaller oral cavities or limited mouth opening difficult [56].

\section{Non-clinical studies}

An infant manikin study, published in 2012, compared the Airtraq with the Pentax airway scope in scenarios where subjects were at rest and when simulated cardiopulmonary resuscitation (CPR) was in place. Although there were no differences in the success of intubation or the glottic views obtained, the times to view the glottis and times to intubation were longer with the Airtraq at rest and during CPR [58].

\section{Clinical evidence}

In children under 5 years old and infants, the Airtraq has shown to provide superior POGO scores but longer times to secure intubation when compared to direct laryngoscopy $[59,60]$. In older children, the intubation time was also longer, but the views were similar between the study groups [60]. Success rates are similar to the Storz VL [58].

A limited number of case reports have been published describing the use of the Airtraq in children ranging in age from 4 weeks to 10 years old and give mixed reviews with no pattern between success rates and child size or airway anomaly $[56,61,62,57]$.

\section{Verdict}

Evidence so far into the use of the Airtraq in children has been on normal airways and has given mixed reviews. Despite its portability, its use is certainly limited due to its size and design. 


\section{Description}

The McGrath series $5 \mathrm{VL}$ is battery operated, fully portable and has single-use blades. It has a camera and light source on the tip of the intubating blade which produces real-time colour video display on the small monitor at the top of the handle. Its design aims to 'simplify intubation of difficult airways and minimize the lifting forces often necessary for successful intubation even on routine airways'. Although it does not come with specific paediatric-sized blades, the length of the blade or 'CameraStick' can be adjusted through three different length settings depending on the patients' size. It is advertised as a VL for infants to adults.

\section{Advantages}

This is a portable device with low maintenance requirements. The disposable blades mean a reduction in disinfection costs and avoidance of potential disease transmission.

\section{Disadvantages}

Its clinical application is restricted in paediatric patients to infants and older children due to the size of the blades.

\section{Non-clinical evidence}

Simulator studies are very limited. In a single adult manikin study, the learning curves associated with indirect laryngoscopes (the GlideScope ${ }^{\circledR}$, the McGrath and the Airtraq) found the McGrath to have a steep learning curve [63]. The study also potentiated that indirect laryngoscopes provided better views of the larynx and potentially less dental trauma. It is uncertain whether this data can be easily applied into paediatric practice.

\section{Clinical evidence}

Clinical trials evaluating the use of the McGrath VL in children are also very few. In a small study presented at the ASA in 2008 found the McGrath to provide 'good conditions for tracheal intubation' in children with predicted normal airways with a mean age of 63 months [64].

Successful use of the McGrath VL has been described in two case reports on children with difficult airways. One featured a 9-year-old with extensive scarring from neck and face burns where fibreoptic laryngoscopy had proved difficult previously. During a planned intubation, the McGrath provided a Cormack and Lehane grade 1 view and intubation was uneventful [65]. A second case was in a 13-year-old with Treacher Collins syndrome and previous failed intubation with direct laryngoscopy. On this occasion, the McGrath gave a grade 1 view and easy intubation whereas the initial direct laryngoscopy with the Macintosh blade gave a grade 4 view [66].

\section{Verdict}

Clinical studies using the McGrath VL in paediatric patients are very limited. However, its use has been described successfully in patients with known difficult airways, suggesting it may have advantages in these cases compared to 


\section{Conclusion}

conventional laryngoscopy. The routine use in expected difficult paediatric airway management cannot be recommended at this stage and requires further supporting data.

Despite increasing clinical trials and emerging case reports, there is not a single paediatric VL that is vastly superior to its competition. Each VL has its proposed benefits, but all come with potential drawbacks, and certainly, there is not one single type to suit all children or airway challenges. It appears proficiency can only be achieved through regular training and clinical use. Cost restrictions and number of clinical opportunities dictate that only one VL is chosen based on departmental needs, preferences and resources. Proficiency in one paediatric VL instead of several is, therefore, essential. Once familiar with the VL, local protocols should be developed to encourage its use in planned normal and difficult airways or as a rescue device. However, proficiency in direct laryngoscopy should supersede all advanced airway techniques. The currently available literature weighs heavily on children with normal airways, and future clinical trials should focus on the use of VL in children with difficult airways.

\section{Compliance with Ethics Guidelines}

\section{Conflict of Interest}

Claire Wallace declares that she has no conflict of interest. Thomas Engelhardt declares that he has no conflict of interest

\section{Human and Animal Rights and Informed Consent}

This article does not contain any studies with human or animal subjects performed by any of the authors.

\section{References and Recommended Reading}

Papers of particular interest, published recently, have been highlighted as:

- Of importance

1. Asai T. Videolaryngoscopes-do they truly have roles in difficult airways? Anesthesiology. 2012;116:515-7.

2. Xue FS, Liu HP, Liu JH, Liao X, Zhang YM. Facilitating endotracheal intubation using the Glidescope ${ }^{\circledR}$ video laryngoscope in children with difficult airways. Pediatr Anesth. 2009;19:908-28.

3. Hirabayashi Y, Otsuka Y. Early clinical experience with Glidescope ${ }^{\circledR}$ video laryngoscope in 20 infants. Pediatr Anesth. 2009;19:800-14.
4. Trevisanuto D, Fornaro E, Verghese C. The GlideScope ${ }^{\circledR}$ video laryngoscope: initial experience in five neonates. Can J Anesth. 2006;53:423-4.

5. Cooper RM. Complications associated with the use of the GlideScope ${ }^{\circledR}$ videolaryngoscope. Can J Anesth. 2007;54:54-7.

6. Nestler C, Reske P, Reske A, Pethke H, Koch T. Pharyngeal wall injury during videolaryngoscopyassisted intubation. Anesthesiology. 2013;118:709. 
7. Leong WL, Lim Y, Sia AT. Palatopharyngeal wall perforation during Glidescope intubation. Anaesth Intensive Care. 2008;36:870-4

8. Holm-Knudsen R. The difficult pediatric airway-a review of new devices for indirect laryngoscopy in children younger than two years of age. Pediatr Anesth. 2011;21:98-103.

9. Sylvia M, Maranda L, Harris KL, Thompson J, Walsh BM. Comparison of success rates using video laryngoscopy versus direct laryngoscopy by residents during a simulated pediatric emergency. Simul Healthc. 2013;8:155-61.

10. Rabiner JE, Auerbach M, Avner JR, Daswani D, Khine $\mathrm{H}$. Comparison of GlideScope video laryngoscope to direct laryngoscopy for intubation of a pediatric simulator by novice physicians. Emerg Med Int. 2013;2013:407547.

11. Fonte M, Oulego-Erroz I, Nadkarni L, Sánchez-Santos L, Iglesias-Vásquez A, Rodriguez-Núñez A. A randomized comparison of the GlideScope videolaryngoscope to the standard laryngoscopy for intubation by pediatric residents in simulated easy and difficult infant airway scenarios. Pediatr Emerg Care. 2011;27:398402.

12. Hurford DM, White MC. A comparison of the Glidescope ${ }^{\circledR}$ and Karl Storz DCI ${ }^{\circledR}$ videolaryngoscopes in a paediatric manikin. Anaesthesia. 2010;65:781-4.

13. White M, Weale N, Nolan J, Sale S, Bayley G. Comparison of the Cobalt Glidescope ${ }^{\circledR}$ videolaryngoscope with conventional laryngoscopy in simulated normal and difficult infant airways. Pediatr Anesth. 2009;19:1108-12.

14. Vlatten A, Litz S, MacManus B, Launcelott S, Soder C. A comparison of the Glidescope video laryngoscope and standard direct laryngoscope in children with immobilized cervical spine. Pediatr Emerg Care. 2012;28:1317-20.

15. Lee J, Park Y, Byon H, Han W, Kim H, Kim C, et al. A comparative trial of the GlideScope ${ }^{\circledR}$ video laryngoscope to direct laryngoscope in children with difficult direct laryngoscopy and an evaluation of the effect of blade size. Anesth Analg. 2013;117:176-81.

This randomized trial focused on children with known or anticipated difficult airways and the effect of blade size. It found the GlideScope VL significantly improved laryngeal views when a smaller blade size was used.

16. Karsli C, Armstrong J, John J. A comparison between the GlideScope ${ }^{\circledR}$ video laryngoscope and direct laryngoscope in pediatric patients with difficult airways-a pilot study. Anaesthesia. 2010;65:353-7.

17. Kim J, Na H, Bae J, Kim D, Kim H, Kim C, et al. GlideScope ${ }^{\circledR}$ video laryngoscope: a randomized clinical trial in 203 paediatric patients. Br J Anaesth. 2008; 101:531-4.

18. Riveros R, Sung W, Sessler DI, Sanchez IP, Mendoza ML, Mascha EJ, et al. Comparison of the Truview PCD ${ }^{\mathrm{TM}}$ and the GlideScope ${ }^{\circledR}$ video laryngoscopes with direct laryngoscopy in pediatric patients: a randomized trial. Can J Anesth. 2013;60:450-7.
19. Lees M, Seal RF, Spady D, Csanyi-Fritz Y, Robinson JL. Randomized trial of success of pediatric anesthesiologists learning to use two video laryngoscopes. Pediatr Anesth. 2013;23:435-9.

20. Kim H, Kim J, Kim H, Kim C, Kim S. A comparison of GlideScope ${ }^{\circledR}$ videolaryngoscopy and direct laryngoscopy for nasotracheal intubation in children. Pediatr Anesth. 2011;21:417-21.

21. Redel A, Karademir F, Schlitterlau A, Frommer M, Scholtz L, Kranke P, et al. Validation of the Glidescope video laryngoscope in pediatric patients. Pediatr Anesth. 2009; 19:667-71.

22. Fiadjoe JE, Gurnaney H, Dalesio N, Sussman E, Zhao $\mathrm{H}$, Zhang $\mathrm{X}$, et al. A prospective randomized equivalence trial of the GlideScope Cobalt ${ }^{\circledR}$ video laryngoscope to traditional direct laryngoscopy in neonates and infants. Anesthesiology. 2012;116:622-8.

23. Karsli C, Der T. Tracheal intubation in older children with severe retro/micrognathia using the GlideScope ${ }^{\circledR}$ Cobalt Infant Video Laryngoscope. Pediatr Anesth. 2010;20:574-83.

24. Xue FS, Liao X, Zhang YM, Luo MP. More maneuvers to facilitate endotracheal intubation using the Bonfils fiberscope in children with difficult airways. Pediatr Anesth. 2009; 19:402-23.

25. Xue FS, Zhang YM, Liao X, Xu YC. Measures to decrease failed intubation with the pediatric Bonfils fiberscope by the obscure vision. Pediatr Anesth. 2009;19:40223.

26. Donogue AJ, Ades AM, Nishisaki A, Deutsch ES. Videolaryngoscopy versus direct laryngoscopy in simulated pediatric intubation. Ann Emerg Med. 2013;61:271-7.

27. Fiadjoe JE, Stricker PA, Hackell RS, Salam A, Gurnaney $\mathrm{H}$, Rehmen MA, et al. The efficacy of the Storz Miller 1 video laryngoscope in a simulated infant difficult intubation. Anesth Analg. 2009;108:1783-6.

28. Donoghue AJ, Ades AM, Nishisaki A, Deutsch ES. Videolaryngoscopy versus standard direct laryngoscopy in simulated pediatric intubation. Ann Emerg Med. 2013;61:271-7.

29. Vlatten A, Aucoin S, Litz S, MacManus B, Soder C. A comparison of Bonfils fiberscope-assisted laryngoscopy and standard direct laryngoscopy in simulated difficult pediatric intubation: a manikin study. Pediatr Anesth. 2010;20:559-65.

30. MacNair D, Baraclough D, Wilson G, Bloch M, Engelhardt T. Pediatric airway management: comparing the Berci-Kaplan video laryngoscope with direct laryngoscopy. Pediatr Anesth. 2009;19:577-80.

31. Vlatten A, Aucoin S, Litz S, Macmanus B, Soder C. A comparison of the Storz video laryngoscope for intubation in the pediatric airway-a randomized clinical trial. Pediatr Anesth. 2009;19:1102-7.

32. Roddy K, Applegate R, Ghazal E, Vadi M, Neiheisel A. A comparison of video laryngoscopy to direct laryngoscopy for endotracheal intubation in children younger than two years of age during manual in-line stabilization. Anesth Analg. 2013;116 5S:S-317. 
33. Sørensen MK, Holm-Knudsen R. Endotracheal intubation with Airtraq $^{\circledR}$ versus Storz ${ }^{\circledR}$

videolaryngoscope in children younger than two years-a randomized pilot study. BMC Anesthesiol. 2012;12:7.

34. Vanderhal AL, Berci G, Simmons CF, Hagiike M. A videolaryngoscope technique for the intubation of the newborn: preliminary report. Pediatrics.

2009;124:e339.

35. Hackell RS, Held LD, Stricker PA, Fiadjoe JE. Management of the difficult infant airway with the Storz video laryngoscope: a case series. Anesth Analg. 2009; 109:763-6.

36. Vlatten A, Aucoin S, Gray A, Soder C. Difficult airway management with the Storz video laryngoscope in a child with Robin Sequence. Pediatr Anesth. 2009;19:695-715.

37. Wald S, Keyes M, Brown A. Pediatric video laryngoscope rescue for a difficult neonatal intubation. Pediatr Anesth. 2008;18:789-807.

38. Viola L, Fiadjoe JE, Stricker PA, Maxwell LG. Video laryngoscopy in infants: one device does not fit all. Pediatr Anesth. 2011;21:980-93.

39. Verchere S, Khalil B, Maddukuri V, Hagberg CA. Use of the DCI video laryngoscope system in a pediatric patient with amniotic band syndrome and craniofacial abnormalities affecting the airway. J Clin Anesth. 2012;24:151-4.

40. Kaufmann J, Laschat M, Hellmich M, Wappler F. A randomized controlled comparison of the Bonfils fiberscope and the GlideScope Cobalt AVL video laryngoscope for visualization of the larynx and intubation of the trachea in infants and small children with normal airways. Pediatr Anesth. 2013;23:913-9.

41. Houston G, Bourke P, Wilson G, Engelhardt T. Bonfils intubating fiberscope in normal paediatric airways. Br J Anaesth. 2010;105:546-7.

42. Bein B, Wortmann F, Meybohm P, Steinfath M, Scholz J, Dörges V. Evaluation of the pediatric Bonfils fiberscope for elective endotracheal intubation. Pediatr Anesth. 2008;18:1040-4.

43. Kaufmann J, Laschat M, Engelhardt T, Hellmich M, Wappler F. Tracheal intubation with the Bonfils fiberscope in the difficult pediatric airway: a comparison with fiberoptic intubation. Pediatr Anesth. 2014. doi: $10.1111 /$ pan. 12523 .

Very recent study comparing the Bonfils fiberscope to gold standard fibreoptic intubation in children with suspected difficult airways. Bonfils provided better quality images, easy to use and potentially faster intubation times.

44. Caruselli M, Zannini R, Giretti R, Rocchi G, Camiletti $G$, Bechi $P$, et al. Difficult intubation in a small for gestational age newborn by Bonfils fiberscope. Pediatr Anesth. 2008;18:976-1014.

45. Laschat M, Kaufmann J, Wappler F. Management of a difficult airway in a child with partial trisomy 1 mosaic using the pediatric Bonfils fiberscope. Pediatr Anesth. 2010;20:195-207.
46. Krishnan P, Thiessen B. Use of the Bonfils intubating fiberscope in a baby with a severely compromised airway. Pediatr Anesth. 2013;23:670-2.

47. Mutlak H, Rolle U, Rosskopf W, Schalk R, Zacharowksi $\mathrm{K}$, Meininger D, et al. Comparison of the TruView infant EV02 PCD ${ }^{\mathrm{TM}}$ and C-MAC video laryngoscope with direct Macintosh laryngoscopy for routine tracheal intubation in infants with normal airways. Clinics. 2014;69:23-7.

48. Sinha R, Rewari V, Varma P, Kumar A. Successful use of $\mathrm{C}$-Mac video laryngoscope in a child with large parapharyngeal mass. Pediatr Anesth. 2014;24:531-3.

49. Oakes ND, Dawar A, Murphy PC. Difficulties using the C-MAC paediatric videolaryngoscope. Anaesthesia. 2013;68:640-54.

50. Wang P, Huang C, Lee Y, Chen T, Lai H. Comparison of 3 video laryngoscopes with the Macintosh in a manikin with easy and difficult simulated airways. Am J Emerg Med. 2013;31:330-8.

51. Inal MT, Memis D, Kargi M, Oktay Z, Sut N. Comparison of the TruView EV02 with Miller laryngoscope in paediatric patients. Eur J Anaesthesiol. 2010;27:950-4.

52. Singh R, Singh P, Vajifdar H. A comparison of TruView infant EV02 laryngoscope with the Miller blade in neonates and infants. Pediatr Anesth. 2009;19:338-42.

53. Tutuncu C, Kaya G, Meyanci G, Tunali Y, Utku T, Vehid S. Comparison of Truview EV02 and Macintosh laryngoscopes in infants. Eur J Anaesthesiol. 2011;28:150.

54. Khan R, Kaul N, Gupte S, Hinai FSAA. Truview PCD ${ }^{\text {тм }}$ eases laryngoscopy and tracheal intubation in patient with cleft lip, palate, and protruding premaxilla. Pediatr Anesth. 2011;21:1268-81.

55. Al-Abri ASZ, Khan RM, Haris A, Kaul N. Successful airway management in a patient with Goldenhar's syndrome using Truview $\mathrm{PCD}^{\circledR}$ laryngoscope. Pediatr Anesth. 2012;22:1224-9.

56. Holm-Knudsen R, White J. The Airtraq may not be the solution for infants with difficult airways. Pediatr Anesth. 2010;20:367-79.

57. Péan D, Desdoits A, Asehnoune K, Lehus C. Airtraq laryngoscope for intubation in Treacher Collins syndrome. Pediatr Anesth. 2009;19:695-715.

58. Tampo A, Suzuki A, Sako S, Kunisawa T, Iwasaki H, Fujita S. A comparison of the Pentax Airway Scope ${ }^{\mathrm{TM}}$ with the Airtraq ${ }^{\mathrm{TM}}$ in an infant manikin. Anaesthesia. 2012;67:881-4.

59. Vlatten A, Fielding A, Bernard A, Litz S, MacManus B, Soder C. Comparison of the Airtraq laryngoscope to the direct laryngoscopy in the pediatric airway. J Pediatr Intensive Care. 2012;1:71-6.

60. White MC, Marsh CJ, Beringer RM, Nolan JA, Choi AYS, Medlock KE, et al. A randomized, controlled trial comparing the Airtraq ${ }^{\mathrm{TM}}$ optical laryngoscope with conventional laryngoscopy in infants and children. Anaesthesia. 2012;67:226-31.

61. Vlatten A, Soder C. Airtraq optical laryngoscope intubation in a 5-month-old infant with a difficult airway because of Robin Sequence. Pediatr Anesth. 2009;19:695-715. 
62. Hirabayashi Y, Shimada N, Nagashima S. Tracheal intubation using pediatric Airtraq ${ }^{\mathrm{TM}}$ optical laryngoscope in a patient with Treacher Collins syndrome. Pediatr Anesth. 2009;19:908-28.

63. Savoldelli GL, Waeber JL, Abegg C, Baeriswyl V, Clergue F, Schiffer E. Learning curves of the Glidescope ${ }^{\circledR}$, the McGrath ${ }^{\circledR}$ and the Airtraq ${ }^{\circledR}$ laryngoscopes in "normal airways": a manikin study. Eur J Anaesthesiol. 2009;26:554-8.

64. Marciniak B, Fayoux P, Laffargue A, Hébrard A, Krivosic-Horber R. Use of the McGrath ${ }^{\circledR}$ Series 5 portable video laryngoscope for tracheal intubation in children. Anesthesiology. 2008;109:A785.

65. Flores AS, Garber SM, Niesen AD, Long TR, Lynch JJ, Wass CT. Clinical application of a novel video camera laryngoscope: a case series venturing beyond the normal airway. J Clin Anesth. 2010;22:201-4.

66. Tsujimoto T, Tanaka S, Yoshiyama Y, Sugiyama Y, Kawamata M. Successful intubation using MCGRATH ${ }^{\circledR}$ MAC in a patient with Treacher Collins Syndrome. Middle East J Anesthesiol. 2014;22:523-5. 